\title{
Edukasi Menjadi Remaja Sehat dan Berkualitas Melalui Program SMART Remaja
}

\author{
Fitriani Mediastuti $^{*}$, Winarsih ${ }^{2}$ \\ 1,2 Program Studi D III Kebidanan, Sekolah Tinggi Ilmu Kesehatan AKBIDYO \\ *fi_medi@yahoo.com
}

\begin{abstract}
ABSTRAK
Remaja memiliki risiko tinggi terkait dengan aktivitas seksual dini dan tidak aman yang akan berdampak terjadinya infeksi menular seksual, HIV/AIDS dan kehamilan berisiko. Adanya informasi yang akurat sangat dibutuhkan oleh remaja dalam membentuk pribadi yang sehat dan berkualitas. Kegiatan pengabdian kepada masyarakat ini dilakukan dengan metode ceramah, pemutaran film edukasi dan diskusi. Kegiatan pengabdian dilaksanakan di SMP PGRI Kasihan Bantul, pada hari Rabu, 23 Januari 2019. Sasaran pengabdian ini adalah siswa SMP dengan jumlah 79 siswa. Materi tersebut diambil dari buku SMART Remaja untuk menggapai remaja yang SMART (Sehat secara Mandiri dan Bertanggungjawab). Mayoritas siswa berusia rata-rata 13 tahun dan tinggal bersama orangtua kandung sebesar 93,67\%. Pendidikan ayah mayoritas SMA yaitu sebesar 55, $70 \%$ dan ibu mayoritas juga SMA yaitu sebesar 59, 49\%. Pekerjaan ayah mayoritas petani/ buruh yaitu sebesar 39.24\% dan ibu mayoritas sebagai ibu rumah tangga sebesar $62.03 \%$. Masih ada siswa yang belum pernah mendapatkan materi kesehatan reproduksi remaja sebesar $27.85 \%$. Secara kuantitatif ada kenaikan skor pengetahuan sebelum dan sesudah penyuluhan, yaitu sebesar 10,45\%. Hal tersebut dapat disimpulkan bahwa edukasi menjadi remaja sehat dan berkualitas melalui program SMART Remaja, efektif. Semakin tinggi pengetahuan yang dimiliki seseorang tentang kesehatan reproduksi remaja, misal dampak dari perilaku berisiko maka akan meningkatkan perilaku positif pada seseorang.
\end{abstract}

Kata Kunci: Edukasi, Remaja, Sehat, SMART Remaja

\section{ABSTRACT}

Adolescents have a high risk of being linked to early and unsafe sexual activities that will have the effect of sexually transmitted infections (STIS), HIV/AIDS and unwanted pregnancies. The existence of accurate information is needed by teenagers in forming a healthy and quality person. This community service activity was carried out with education, film and discussion methods. The service activities were held at the poor PGRI SMP Bantul on Wednesday, January 23, 2019. The target of this service was junior high school students with a total of 79 students. The material is taken from the SMART Teen book to reach young people who are SMART. The majority of students aged 13 years and living with biological parents were 93.67\%. The majority of high school fathers' education is 55, 70\% and majority mothers are also high school, which is $59,49 \%$. The work of the majority of farmers / laborers is $39.24 \%$ and the majority of mothers as housewives are 62.03\%. There are still students who have never received adolescent reproductive health material by 27.85\%. Quantitatively there is an increase in knowledge scores before and after education, 10,45\%. It can be concluded that education is becoming a healthy and qualified teenager through the SMART SMART program, effective. The higher the knowledge someone has about reproductive health of adolescents, for example the impact of risky behavior will increase positive behavior in someone.

Keywords: Education, Adolescent, Healthy, SMART Teenagers 


\section{PENDAHULUAN}

Kesehatan reproduksi dan seksual remaja telah diakui sebagai masalah kesehatan yang penting dan telah menjadi fokus perhatian global selama bertahuntahun. Dalam dua puluh tahun sejak kesehatan reproduksi remaja diidentifikasi sebagai area untuk tindakan spesifik pada Konferensi Internasional tentang Kependudukan dan Pembangunan pada tahun 1994, upayaupaya substansial telah diarahkan untuk memahami dan menangani kebutuhan khusus populasi ini (RajapaksaHewageegana, Piercy, Salway, \& Samarage, 2015).

Remaja memiliki risiko tinggi terkait dengan aktivitas seksual dini dan tidak aman yang akan berdampak terjadinya infeksi HIV / AIDS, infeksi menular seksual (IMS) dan kehamilan yang tidak diinginkan. Perilaku seksual berisiko yang meningkat di kalangan remaja berujung pada pemikiran bahwa dimungkinkan karena kurangnya pengetahuan tentang seks dan seksualitas, sehingga memicu remaja untuk melakukan risiko seksual (Rashid \& Mwale, 2016).

Di Indonesia, berdasarkan data Survei Demografi dan Kesehatan Indonesia (SDKI) (2012), angka fertilitas total untuk periode tiga tahun terakhir adalah 2,6 anak per wanita. Angka tersebut tidak berubah sejak SDKI 20022003. Data SDKI (2012) juga menyebutkan bahwa sebanyak $10 \%$ remaja wanita umur 15-19 tahun pernah melahirkan atau sedang hamil anak pertama. Alasan remaja melakukan hubungan seksual pertama diantaranya terjadi begitu saja, adanya rasa penasaran, dipaksa oleh pasangan, dijanjikan akan dinikahi dan adanya pengaruh teman sebaya(Fitri Mediastuti, 2014).

Intervensi dalam melindungi perilaku seksual berisiko pada remaja sangat dibutuhkan dan telah dievaluasi. Beberapa program yang dijalankan memiliki keberhasilan mengubah mindset remaja dalam berfikir untuk masa depan. Salah satu program tersebut adalah program SMART Remaja. Edukasi tentang membentuk karakter remaja yang sehat sangat dibutuhkan oleh remaja. Sumber informasi yang dapat menjadi acuan dalam membentuk pribadi yang sehat dan berkualitas sangat dibutuhkan.

\section{METODE}

Kegiatan pengabdian kepada masyarakat ini dilakukan dengan metode ceramah, pemutaran film, diskusi dan tanya jawab. Sasaran pengabdian ini adalah siswa SMP. Peserta berjumlah 79 siswa yang terbagi dalam tiga kelas, sehingga pelaksanaan edukasi ini dilakukan tiga sesi karena agar lebih efektif dan leluasa dalam diskusi. Kegiatan pengabdian dilaksanakan di SMP PGRI Kasihan Bantul Yogyakarta pada hari Rabu, 23 Januari 2019. Media yang digunakan adalah media power point dan juga film edukasi untuk remaja. Materi kegiatan diambil dari program SMART Remaja. Dalam pelaksanaan pengabdian, sebelum dan sesudah pemberian materi, dilakukan pengisian kuesioner tentang karakteristik peserta serta pengetahuan seputar kesehatan reproduksi remaja (isi kuesioner disesuaikan dengan materi).

Materi dalam kegiatan pengabdian kepada masyarakat ini sesuai dengan kebutuhan siswa SMP. Materi penyuluhan yang disampaikan meliputi: mengenal harga diri, membuat pilihan hidup sehat, menjalin komunikasi yang efektif, bersikap positif dan perencanaan masa depan. Materi tersebut diambil dari buku SMART Remaja untuk menggapai remaja yang SMART (Sehat secara Mandiri dan Bertanggungjawab). Materi tersebut bertujuan menjadikan remaja yang mampu bertanggung jawab terhadap tubuhnya sendiri. Materi film berupa film edukasi tentang dampak dari kehamilan remaja. Film tersebut menceritakan kisah dua orang sahabat yang masih sekolah di SMP, namanya Dodi dan Doni. Doni memiliki perilaku yang berisiko yakni melakukan pacaran, sedangkan Doni lebih memilih tidak mau pacaran dan menghabiskan waktu luangnya dengan 
mengembangkan bakatnya yaitu bermain basket. Akhir cerita, Dodi terlibat masalah yaitu Sinta (pacarnya) mengalami kehamilan di luar nikah, dan akhirnya Sinta meninggal karena terjadi perdarahan hebat. Dodi pun mengalami depresi dan menyesali perbuatannya. Sementara Doni menjadi pemain basket yang hebat (Fitriani Mediastuti, Ismail, Prabandari, \& Emilia, 2017).

\section{HASIL DAN PEMBAHASAN}

Proses kegiatan penyuluhan berjalan lancar. Siswa dan siswi mengikuti kegiatan ini dengan aktif mendengarkan maupun bertanya. Penyampaian materi yang dilakukan dengan santai tapi serius membuat siswa dan siswi lebih terbuka. Materi film singkat jelas namun penuh makna dapat tersampaikan ke siswa. Pada saat sesi diskusi, siswa pun aktif bertanya.

Karakteristik peserta kegiatan ini yaitu siswa dan siswi SMP PGRI Kasihan Bantul dengan karakteristik seperti yang dijelaskan pada Tabel 1.

Tabel 1. Karakteristik Siswa Peserta Penyuluhan

\begin{tabular}{|c|c|c|}
\hline Keterangan & $\mathbf{f}$ & $\begin{array}{c}\text { Persentase } \\
(\%)\end{array}$ \\
\hline \multicolumn{3}{|l|}{ Jenis kelamin } \\
\hline 1. Laki-laki & 37 & 46.84 \\
\hline 2. Perempuan & 42 & 53.16 \\
\hline Total & 79 & 100 \\
\hline \multicolumn{3}{|l|}{ Usia } \\
\hline 1. 12 & 11 & 13.92 \\
\hline 2. 13 & 39 & 49.37 \\
\hline 3. 14 & 21 & 26.58 \\
\hline 4. 15 & 7 & 8.86 \\
\hline 5. 16 & 1 & 1.27 \\
\hline Total & 79 & 100 \\
\hline \multicolumn{3}{|l|}{ Struktur Keluarga } \\
\hline 1. Tinggal bersama kedua orangtua kandung & 74 & 93.67 \\
\hline 2. Tidak tinggal bersama kedua orangtua kandung & 5 & 6.33 \\
\hline Total & 79 & 100 \\
\hline \multicolumn{3}{|l|}{ Pendidikan terakhir ayah } \\
\hline 1. Perguruan tinggi & 7 & 8.86 \\
\hline 2. SMA & 44 & 55.70 \\
\hline 3. SMP & 13 & 16.46 \\
\hline 4. SD & 13 & 16.46 \\
\hline 5. Tidak tahu & 2 & 2.53 \\
\hline Total & 79 & 100 \\
\hline \multicolumn{3}{|l|}{ Pekerjaan Ayah } \\
\hline 1. Petani/ Buruh & 31 & 39.24 \\
\hline 2. Pedagang/Wiraswasta & 17 & 21.52 \\
\hline 3. PNS/ TNI/POLRI & 8 & 10.13 \\
\hline 4. Karyawan Swasta & 21 & 26.58 \\
\hline 5. Petani/ Buruh & 2 & 2.53 \\
\hline Total & 79 & 100 \\
\hline \multicolumn{3}{|l|}{ Pendidikan terakhir ibu } \\
\hline 1. Perguruan tinggi & 6 & 7.59 \\
\hline 2. SMA & 47 & 59.49 \\
\hline 3. SMP & 16 & 20.25 \\
\hline 4. SD & 7 & 8.86 \\
\hline 5. Tidak tahu & 3 & 3.80 \\
\hline
\end{tabular}




\begin{tabular}{lll}
\hline \multicolumn{1}{c}{ Keterangan } & \multicolumn{1}{c}{ f } & \multicolumn{1}{c}{$\begin{array}{c}\text { Persentase } \\
(\%)\end{array}$} \\
\hline Total & 79 & 100 \\
Pekerjaan ibu & & \\
1. Ibu Rumah Tangga & 49 & 62.03 \\
2. Petani/ Buruh & 7 & 8.86 \\
3. Pedagang/ Wiraswasta & 15 & 18.99 \\
4. PNS/ TNI/POLRI & 8 & 10.13 \\
Total & 79 & 100 \\
Sudah pernah mendapatkan materi kesehatan & & \\
reproduksi remaja/ belum & & \\
1. Sudah & 57 & 72.15 \\
2. Belum & 22 & 27.85 \\
Total & 79 & 100 \\
Asal Informasi & & \\
1. Teman & 2 & 2.53 \\
2. Orangtua & 11 & 13.92 \\
3. Guru & 30 & 37.97 \\
4. BKKBN/ Dinas Kesehatan & 11 & 13.92 \\
5. TV/ Radio/Majalah/ Koran/ Internet & 2 & 2.53 \\
6. Lainnya & 23 & 29.11 \\
Total & 79 & 100 \\
\hline
\end{tabular}

Mayoritas peserta dalam pengabdian ini adalah siswa perempuan yaitu 53,16\%. Usia siswa mayoritas 13 tahun. Posisi remaja ini berada pada remaja awal yang artinya pada saat usia tersebut terjadi perubahan fisik pada remaja yang dimulai dengan pubertas. Berdasarkan sisi kognitif, pada saat usia tersebut terdapat pertambahan kemampuan berfikir abstrak. Pada saat usia remaja awal, remaja hanya tertarik pada kejadian saat ini dan belum memikirkan masa depan. Ditinjau dari segi emosional, mereka berusaha keras untuk menemukan jati diri. Pada saat tersebut pengaruh teman sebaya sangat kuat. Di saat usia tersebut, remaja mudah menjadi emosi dan mudah kembali bersifat seperti anak-anak (American Academy of Child and Adolescent's Facts for Families, 2008).

Berdasarkan karakteristik pada Tabel 1, pendidikan ayah mayoritas SMA yaitu sebesar 55, $70 \%$ dan pendidikan ibu mayoritas juga SMA yaitu sebesar 59, $49 \%$. Pekerjaan ayah mayoritas petani/ buruh yaitu sebsar $39.24 \%$ dan pekerjaan ibu mayoritas ibu rumah tangga yaitu sebesar $62.03 \%$. Mayoritas siswa tinggal bersama orangtua kandung, yaitu sebesar 93,67\%. Meski demikian informasi tentang kesehatan reproduksi/ seksual remaja masih belum memuaskan. Hal tersebut didukung dengan data remaja yang mendapatkan informasi tentang kesehatan reproduksi dengan sumber informasi dari orang tua hanya $13,92 \%$. Hal tersebut sesuai juga dengan penelitian Tegegn et al. (Tegegn, Yazachew, \& Gelaw, 2008) yang menyebutkan bahwa peran profesional kesehatan dan keluarga sebagai sumber informasi untuk remaja rendah. Oleh karena itu, harus ditingkatkan dengan menggunakan semua pemangku kepentingan yang lebih terintegrasi terutama keluarga remaja dan profesional kesehatan yang memiliki peran vital untuk memastikan pengetahuan yang memadai dan sikap yang menguntungkan untuk pemanfaatan kesehatan reproduksi.

Siswa yang sudah mendapat materi kesehatan reproduksi lebih ke arah pelajaran biologi, misalnya bagaimana sel telur bertemu dengan sel sperma. Sementara materi yang terkait dengan bagaimana cara mencegah perilaku seksual berisiko tidak diberikan secara 
detail, khususnya dampaknya secara medis. Dalam pengabdian edukasi ini digunakan media film edukasi agar peserta lebih mudah memahami dan mengingatnya. Efektifitas penggunaan media film juga telah terbukti pada penelitian Ngcobo (Ngcobo, 2015) yaitu temuan menunjukkan bahwa melalui analisis film sebagai intervensi pedagogis, menjadikan peserta didik tidak hanya memperoleh keterampilan analitis dan interpretatif tetapi juga keterampilan berpikir kritis, terutama dalam konteksnya. Wonderly (Wonderly, 2009) juga menyatakan bahwa media film edukasi untuk anak dapat menjadi instrument pendidikan moral.

Sebelum dan setelah dilakukan penyuluhan, pengetahuan siswa dan siswi diukur dengan mengisi kuesioner. Kuesioner sudah dilakukan validasi karena mengadopsi dari penelitian Mediastuti (2017). Hasil analisis dari pengetahuan dapat dilihat pada Gambar 1 .

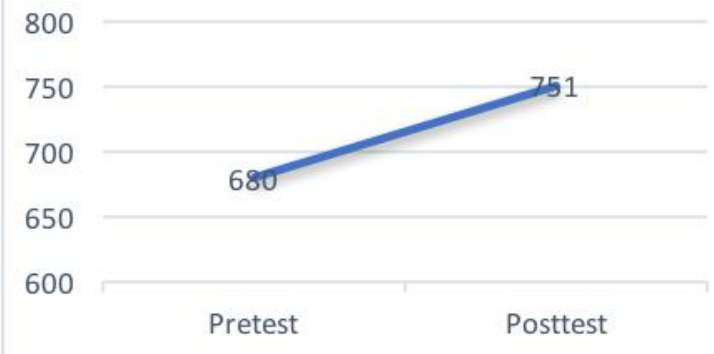

Gambar 1. Pengetahuan Remaja Sebelum dilakukan Penyuluhan dan Setelah dilakukan Penyuluhan

Berdasarkan Gambar 1, dapat dilihat bahwa ada kenaikan pengetahuan sebelum dan sesudah penyuluhan ada kenaikan sekitar 10,45\%. Hal tersebut dapat disimpulkan bahwa penyuluhan tersebut efektif. Semakin tinggi pengetahuan yang dimiliki seseorang tentang kesehatan reproduksi remaja, missal dampak dari perilaku berisiko maka akan meningkatkan perilaku positif pada seseorang.

\section{Penelitian}

Rajapaksa-

Hewageegana et al. (2015) menyatakan bahwa pengetahuan dibutuhkan oleh siswa dan siswi untuk membuat keputusan seksual dan reproduksi yang terinformasi dan untuk melindungi mereka dari perilaku berisiko. Sebuah survei remaja nasional yang dilakukan hampir 10 tahun dengan anak berusia 1519 tahun melaporkan tingkat pengetahuan yang sangat rendah tentang proses reproduksi, kontrasepsi dan kesehatan seksual dalam kelompok remaja sekolah dan putus sekolah. Penelitian (Thobejane, 2015) menyebutkan bahwa kurangnya informasi di kalangan anak muda tentang pendidikan seks masih menjadi masalah di beberapa negara karena orang tua tidak punya cukup waktu untuk duduk bersama anak-anak mereka dan berbicara tentang seks. Oleh karena itu, untuk mengatasinya di beberapa tempat diberikan pendidikan seks di sekolah. Pendidikan seksual di sekolah bertujuan untuk mengatasi masalah perilaku seksual berisiko, sehingga akan terbentuk remaja yang sehat dan berkualitas. Hal tersebut sesuai dengan penelitian yang dilakukan oleh (Menna, Ali, \& Worku, 2015), yang menyatakan bahwa meskipun pemberian intervensi pendidikan seksual pada siswa singkat, siswa dalam kelompok intervensi menunjukkan perubahan positif pada pengetahuan secara komprehensif terkait HIV dan menunjukkan minat yang lebih baik untuk melakukan tes HIV dalam waktu dekat. Selanjutnya, perubahan positif pada perilaku seksual berisiko dilaporkan dari kelompok intervensi. Hal serupa juga dijelaskan pada penelitian yang dilakukan oleh (Sani, Abraham, Denford, \& Ball, 2016), yaitu bahwa pendidikan kesehatan seksual berbasis sekolah berpotensi mempromosikan penggunaan kondom di kalangan anak muda di Indonesia dan Sub-Sahara Afrika.

Oleh karena hal tersebut, peningkatan edukasi untuk membentuk remaja sehat dan berkualitas sangat penting.

\section{SIMPULAN}

Perilaku seksual berisiko di kalangan remaja masih memprihatinkan. Hal tersebut diakibatkan salah satu faktornya adalah kurangnya pengetahuan 
tentang seks dan seksualitas. Oleh karena itu dibutuhkan edukasi pada remaja terkait kesehatan reproduksi khususnya dalam mencegah perilaku berisiko dan membentuk remaja yang sehat. Dalam pengabdian ini edukasi kepada remaja agar dapat menjadi remaja yang sehat dan berkualitas dilakukan melalui program SMART Remaja dan berjalan lancar. Siswa dan siswi memahami cara melakukan pencegahan perilaku berisiko dan mampu memahami dalam merencanakan masa depan.

Saran untuk pengabdi selanjutnya yaitu, perlu ditingkatkan kegiatan pengabdian sejenis dan lebih continue dengan kerjasama dari berbagai stakeholder terkait agar lebih optimal dan berkesinambungan.

\section{DAFTAR PUSTAKA}

Mediastuti, F. (2014). Analisis

Kebutuhan Sumber Informasi dalam Upaya Pencegahan Kehamilan pada Remaja. Jurnal Studi Pemuda, 3(1), $17-24$.

Mediastuti, F., Ismail, D., Prabandari, Y. S., \& Emilia, O. (2017). Smart remaja, Menjawab Tantangan Pencegahan Kehamilan Pada Remaja SMP (1st ed.). Yogyakarta: CV.Mine.

Menna, T., Ali, A., \& Worku, A. (2015). Effects of peer education intervention on HIV / AIDS related sexual behaviors of secondary school students in Addis Ababa, Ethiopia : a quasi-experimental study. Reproductive Health, 1-8. https://doi.org/10.1186/s12978-0150077-9

Ngcobo, N. (2015). Agenda Empowering women for gender equity The use of film as an intervention in addressing gender violence : Experiences in a South African secondary school article The use of film as an intervention in addressing gender violence : Experiences in a South . Agenda, 0(0), 1-10. https://doi.org/10.1080/10130950.20 15.1056586
Rajapaksa-Hewageegana, N., Piercy, H., Salway, S., \& Samarage, S. (2015). Sexual and reproductive knowledge, attitudes and behaviours in a school going population of Sri Lankan adolescents. Sexual and Reproductive Healthcare, 6(1), 3-8. https://doi.org/10.1016/j.srhc.2014.0 8.001

Rashid, S., \& Mwale, M. (2016). The Effects of Sex Education on the Risky Sexual Behaviour of School Going Adolescents: A Case Study of Mbenjere Secondary, Ntaja and Nsanama Community Day Secondary Schools. Psychology \& Developing Societies, 28(1), 126138.

https://doi.org/10.1177/0971333615 622910

Sani, A. S., Abraham, C., Denford, S., \& Ball, S. (2016). School-based sexual health education interventions to prevent STI / HIV in sub- Saharan Africa : a systematic review and meta-analysis. BMC Public Health. https://doi.org/10.1186/s12889-0163715-4

Tegegn, A., Yazachew, M., \& Gelaw, Y. (2008). Reproductive Health Knowledge and Attitude among Adolescents : A community based study in Jimma Town, Southwest Ethiopia.

Thobejane, T. D. (2015). Factors Contributing to Teenage Pregnancy in South Africa: The Case of Matjitjileng Village. Journal of Sociology and Social Anthropology, 6(2), 273-277. https://doi.org/10.1080/09766634.20 15.11885667

Wonderly, M. (2009). Children 's film as an instrument of moral education Children' $\mathrm{s}$ film as an instrument of moral education, (December 2014), 37-41.

https://doi.org/10.1080/0305724080 2601466 